\title{
Special Issue on Selected Papers from IEEE ICKII 2019
}

\author{
Teen-Hang Meen ${ }^{1, *} \mathbb{D}$, Wenbing Zhao ${ }^{2} \mathbb{D}$ and Cheng-Fu Yang ${ }^{3, *}$ \\ 1 Department of Electronic Engineering, National Formosa University, Yunlin 632, Taiwan \\ 2 Department of Electrical Engineering and Computer Science, Cleveland State University, Cleveland, \\ OH 44011, USA; w.zhao1@csuohio.edu \\ 3 Department of Chemical and Materials Engineering, National University of Kaohsiung, \\ Kaohsiung 811, Taiwan \\ * Correspondence: thmeen@nfu.edu.tw (T.-H.M.); cfyang@nuk.edu.tw (C.-F.Y.)
}

Received: 23 March 2020; Accepted: 3 April 2020; Published: 14 April 2020

check for updates

\begin{abstract}
This Special Issue on "Selected papers from IEEE ICKII 2019" selected 13 excellent papers from 260 papers presented in IEEE ICKII 2019 on topics in energies. The fields include: energy fundamentals, energy sources and energy carriers, energy exploration, intermediate and final energy use, energy conversion systems, and energy research and development. The main goal of this Special Isue is to discover new scientific knowledge relevant to the topic of energies.
\end{abstract}

Keywords: energy sources and energy carriers; energy conversion systems; energy research and development

The 2nd IEEE International Conference on Knowledge Innovation and Invention 2019 (IEEE ICKII 2019) was held in Seoul, South Korea on 12-15 July 2019. It provided a unified communication platform for researchers in the topics of information technology, innovation design, communication science and engineering, industrial design, creative design, applied mathematics, computer science, electrical and electronic engineering, mechanical and automation engineering, green technology and architecture engineering, material science, and other related fields. This Special Issue on "Selected papers from IEEE ICKII 2019" selected 13 excellent papers from 260 papers presented in IEEE ICKII 2019 on topics in energies. The fields include: energy fundamentals, energy sources and energy carriers, energy exploration, intermediate and final energy use, energy conversion systems, and energy research and development. The main goal of this Special Issue is to discover new scientific knowledge relevant to the topic of energies.

\section{The Topic of Energies and its Applications}

This Special Issue on "Selected papers from IEEE ICKII 2019" selected 13 excellent papers from 260 papers presented in IEEE ICKII 2019 on topics in energies. The published papers are introduced as follows:

Hwang et al. reported on "Optimization and Application for Hydraulic Electric Hybrid Vehicle" [1]. In this research, the rule-based control strategy was implemented as the energy distribution management strategy first, and then the genetic algorithm was utilized to conduct global optimization strategy analysis. The results from the genetic algorithm were employed to modify the rule-based control strategy to improve the electricity economic performance of the vehicle. The simulation results show that the electricity economic performance of the designed hydraulic hybrid vehicle was improved by $36.51 \%$ compared to that of a pure electric vehicle. The performance of energy consumption after genetic algorithm optimization was improved by $43.65 \%$.

Liao reported "A Step Up/Down Power-Factor-Correction Converter with Modified Dual Loop Control" [2]. In this study, A step up/down AC/DC converter with a modified dual loop control is proposed. The step up/down AC/DC converter features the bridgeless characteristic which can 
reduce bridge-diode conduction losses. Based on the step up/down AC/DC converter, a modified dual loop control scheme is proposed to achieve input current shaping and output voltage regulation. Fewer components are needed compared with the traditional bridge and bridgeless step up/down AC/DC converters. In addition, the intermediate capacitor voltage stress can be reduced. Furthermore, the top and bottom switches still have a zero-voltage turn-on function during the negative and positive half-line cycle, respectively. Hence, the thermal stresses can also be reduced and balanced. Simulation and experimental results are provided to verify the validity of the proposed step up/down $\mathrm{AC} / \mathrm{DC}$ converter and its control scheme.

Wu et al., reported "The Optimal Control of Fuel Consumption for a Heavy-Duty Motorcycle with Three Power Sources Using Hardware-in-the-Loop Simulation" [3]. This study presents a simulation platform for a hybrid electric motorcycle with an engine, a driving motor, and an integrated starter generator (ISG) as three power sources. This platform also consists of the driving cycle, driver, lithium-ion battery, continuously variable transmission (CVT), motorcycle dynamics, and energy management system models. Two Arduino DUE microcontrollers integrated with the required circuit to process analog-to-digital signal conversion for input and output are utilized to carry out a hardware-in-the-loop (HIL) simulation. A driving cycle called the worldwide motorcycle test cycle (WMTC) is used for evaluating the performance characteristics and response relationship among subsystems. Control strategies called rule-based control (RBC) and equivalent consumption minimization strategy (ECMS) are simulated and compared with the purely engine-driven operation. The results show that the improvement percentages for equivalent fuel consumption and energy consumption for RBC and ECMS using the pure software simulation were $17.74 \% / 18.50 \%$ and $42.77 \% / 44.22 \%$ respectively, while those with HIL were $18.16 \% / 18.82 \%$ and $42.73 \% / 44.10 \%$, respectively.

Tsai et al., reported "Optimal Configuration with Capacity Analysis of a Hybrid Renewable Energy and Storage System for an Island Application" [4]. This study uses a Philippine offshore island to optimize the capacity configuration of a hybrid energy system (HES). A thorough investigation was performed to understand the operating status of existing diesel generator sets and load power consumption, and to collect the statistics of meteorological data and economic data. Using the Hybrid Optimization Models for Energy Resources (HOMER) software we simulated and analyzed the techno-economics of different power supply systems containing stand-alone diesel systems, photovoltaic (PV)-diesel HES, wind-diesel HES, PV-wind-diesel HES, PV-diesel-storage HES, wind-diesel-storage HES, and PV-wind-diesel-storage HES. In addition to the lowest cost of energy (COE), capital cost, fuel saving and occupied area, the study also uses entropy weight and the Technique for Order Preference by Similarity to an Ideal Solution (TOPSIS) method to evaluate the optimal capacity configuration. The proposed method can also be applied to design hybrid renewable energy systems for other off-grid areas.

Li et al., reported "Integrated Analysis of Influence of Multiple Factors on Transmission Efficiency of Loader Drive Axle" [5]. In this study, a loader drive axle digital model was built using 3D commercial software. On the basis of this model, the transmission efficiency of the main reducing gear, the differential planetary mechanism, and the wheel planetary reducing gear of the loader drive axle were studied. The functional relationship of the transmission efficiency of the loader drive axle was obtained, including multiple factors: the mesh friction coefficient, the mesh power loss coefficient, the normal pressure angle, the helix angle, the offset amount, the speed ratio, the gear ratio, and the characteristic parameters. This revealed the influence law of the loader drive axle by the mesh friction coefficient, mesh power loss coefficient, and speed ratio. The research results showed that the transmission efficiency of the loader drive axle increased with the speed ratio, decreased when the mesh friction coefficient and the mesh power loss coefficient increased, and that there was a greater influence difference in the transmission efficiency of the loader drive axle.

Yu et al., reported "Management and Distribution Strategies for Dynamic Power in a Ship's Micro-Grid System Based on Photovoltaic Cell, Diesel Generator, and Lithium Battery" [6]. This study examines the stable parallel operation of a ship's micro-grid system through a dynamic power 
management strategy involving a step change in load. With cruise ships in mind, the authors construct a micro-grid system consisting of photovoltaics (PV), a diesel generator (DG), and a lithium battery, and establish a corresponding simulation model. The authors analyze the system's operating characteristics under different working conditions and present the mechanisms that influence the power quality of the ship's micro-grid system. Based on an analysis of the power distribution requirements under different working conditions, the authors design a power allocation strategy for the micro-grid system. Next the authors propose an optimization allocation strategy for dynamic power based on fuzzy control and a load current feed-forward method, and finally, the authors simulate the whole system. Through this study, the authors prove that the proposed power management strategy not only verifies the feasibility and correctness of the ship's micro-grid structure and control strategy, but also greatly improves the reliability and stability of the ship's operation.

Lin et al., reported "Analysis of Energy Flux Vector on Natural Convection Heat Transfer in Porous Wavy-Wall Square Cavity with Partially-Heated Surface" [7]. This study utilizes the energy-flux-vector method to analyze the heat transfer characteristics of natural convection in a wavy-wall porous square cavity with a partially heated bottom surface. The effects of the modified Darcy number, modified Rayleigh number, modified Prandtl number, and length of the partially heated bottom surface on the energy-flux-vector distribution and mean Nusselt number are examined. The results show that when a low modified Darcy number with any value of modified Rayleigh number is given, the recirculation regions are not formed in the energy-flux-vector distribution within the porous cavity. Therefore, a low mean Nusselt number is presented. The recirculation regions still do not form, and thus the mean Nusselt number has a low value when a low modified Darcy number with a high modified Rayleigh number is given.

Luo et al., reported "Performance Enhancement of Hybrid Solid Desiccant Cooling Systems by Integrating Solar Water Collectors in Taiwan" [8]. In this study, a solar-assisted hybrid Solid Desiccant Cooling System (SDCS) was developed, in which solar-heated water is used as an additional heat source for the regeneration process, in addition to recovering heat from the condenser of an integrated heat pump. A solar thermal collector sub-system is used to generate solar regenerated water. Experiments were conducted in the typically hot and humid weather of Taichung, Taiwan, from the spring to fall seasons. The experimental results show that the overall performance of the system in terms of power consumption can be enhanced by approximately $10 \%$ by integrating a solar-heated water heat exchanger, in comparison to the hybrid SDCS system. The results show that the system performs better when the outdoor humidity ratio is high. In addition, regarding the effect of ambient temperature on the coefficient of performance (COP) of the systems, a critical value of outdoor temperature exists. The COP of the systems gradually rises with the increase in ambient temperature. However, when the ambient temperature is greater than the critical value, the COP gradually decreases with the increase in ambient temperature. The critical outdoor temperature of the hybrid SDCS is from 26 to $27^{\circ} \mathrm{C}$, and the critical temperature of the solar-assisted hybrid SDCS is from 27 to $30^{\circ} \mathrm{C}$.

Hsueh et al. reported "Condition Monitor System for Rotation Machine by CNN with Recurrence Plot" [9]. In this paper, the authors introduce an effective framework for the fault diagnosis of 3-phase induction motors. The proposed framework mainly consists of two parts. The first part explains the preprocessing method, in which the time-series data signals are converted into two-dimensional (2D) images. The preprocessing method generates recurrence plots (RP), which represent the transformation of time-series data such as 3-phase current signals into 2D texture images. The second part of the paper explains how the proposed convolutional neural network (CNN) extracts the robust features to diagnose the induction motor's fault conditions by classifying the images. The generated RP images are considered as input for the proposed $\mathrm{CNN}$ in the texture image recognition task. The proposed framework is tested on the dataset collected from different 3-phase induction motors working with different failure modes. The experimental results of the proposed framework show its competitive performance over traditional methodologies and other machine learning methods. 
Chen et al., reported "Design of a Logistics System with Privacy and Lightweight Verification" [10]. This study designs a secure logistics system, with anonymous and lightweight verification, in order to meet the following requirements: mutual authentication, non-repudiation, anonymity, integrity, and a low overhead for the logistics environment. A buyer could check the goods and know if the parcel has been exchanged by a malicious person. Moreover, the proposed scheme not only presents a solution to meet the logistics system's requirements, but also to reduce both computational and communication costs.

Chang et al. reported on the "Current Control of the Permanent-Magnet Synchronous Generator Using Interval Type-2 T-S Fuzzy Systems" [11]. In this study, the current control of the permanent-magnet synchronous generator (PMSG) using an interval type-2 (IT2) Takagi-Sugeno (T-S) fuzzy systems is designed and implemented. PMSG is an energy conversion unit widely used in wind energy generation systems and energy storage systems. Its performance is determined by the current control approach. IT2 T-S fuzzy systems are implemented to deal with the nonlinearity of a PMSG system in this paper. First, the IT2 T-S fuzzy model of a PMSG is obtained. Second, the IT2 T-S fuzzy controller is designed based on the concept of parallel distributed compensation (PDC). Next, the stability analysis can be conducted through the Lyapunov theorem. Accordingly, the stability conditions of the closed-loop system are expressed in Linear Matrix Inequality (LMI) form. The AC power from a PMSG is converted to DC power via a three-phase six-switch full bridge converter. The six-switch full bridge converter is controlled by the proposed IT2 T-S fuzzy controller. The analog-to-digital (ADC) conversion, rotor position calculation and duty ratio determination are digitally accomplished by the microcontroller. Finally, the simulation and experimental results verify the performance of the proposed current control.

Lin et al., reported "The Optimal Energy Dispatch of Cogeneration Systems in a Liberty Market" [12]. This paper investigates the cogeneration systems of industrial users and collects fuel consumption data and data concerning the steam output of boilers. On the basis of the relation between the fuel enthalpy and steam output, the Least Squares Support Vector Machine (LSSVM) is used to derive boiler and turbine Input/Output $(\mathrm{I} / \mathrm{O})$ operation models to provide fuel cost functions. The $\mathrm{CO}_{2}$ emission of pollutants generated by various types of units is also calculated. The objective function is formulated as a maximal profit model that includes profit from steam sold, profit from electricity sold, fuel costs, costs of exhausting carbon, wheeling costs, and water costs. By considering Time-of-Use (TOU) and carbon trading prices, the profits of a cogeneration system in different scenarios are evaluated. By integrating the Ant Colony Optimization (ACO) and Genetic Algorithm (GA), an Enhanced ACO (EACO) is proposed to come up with the most efficient model. The EACO uses a crossover and mutation mechanism to alleviate the local optimal solution problem and to seek a system that offers an overall global solution using competition and selection procedures. The results show that these mechanisms provide a good direction for the energy trading operations of a cogeneration system. This approach also provides a better guide for operation dispatch to use in determining the benefits accounting for both cost and the environment in a liberty market.

Hsu et al. reported "Article Numerical Simulation of Crystalline Silicon Heterojunction Solar Cells with Different p-Type a-SiOx Window Layer" [13]. In this study, p-type amorphous silicon oxide (a-SiOx) films are deposited using a radio-frequency, inductively coupled plasma chemical vapor deposition system. Effects of the $\mathrm{CO}_{2}$ gas flow rate on film properties and crystalline silicon heterojunction $(\mathrm{HJ})$ solar cell performance are investigated. The experimental results show that the band gap of the a-SiOx film can reach $2.1 \mathrm{eV}$ at $\mathrm{CO}_{2}$ flow rate of 10 standard cubic centimeters per minute ( $\mathrm{sccm}$ ), but the conductivity of the film deteriorates. In the device simulation, the transparent conducting oxide and contact resistance are not taken into account. The electrodes are assumed to be perfectly conductive and transparent. The simulation result shows that there is a tradeoff between the increase in the band gap and the reduction in conductivity at an increasing $\mathrm{CO}_{2}$ flow rate, and the balance occurs at the flow rate of six sccm, corresponding to a band gap of $1.95 \mathrm{eV}$, an oxygen content of $34 \%$, and a conductivity of $3.3 \mathrm{~S} / \mathrm{cm}$. The best simulated conversion efficiency is $25.58 \%$, with an open-circuit voltage of $741 \mathrm{mV}$, a short-circuit current density of $42.3 \mathrm{~mA} / \mathrm{cm}^{2}$, and a fill factor of $0.816 \%$. 
Author Contributions: Writing and reviewing all papers, T.-H.M.; English editing, W.Z.; checking and correcting the manuscript, C.-F.Y. All authors have read and agreed to the published version of the manuscript.

Funding: This research received no external funding.

Acknowledgments: The guest editors would like to thank the authors for their contributions to this Special Issue and all the reviewers for their constructive reviews. We are also grateful to Chloe $\mathrm{Wu}$, the Assistant Editor of Energies, for her time and efforts in the publication of this special issue for Energies.

Conflicts of Interest: The authors declare no conflict of interest.

\section{References}

1. Hwang, H.Y.; Lan, T.S.; Chen, J.S. Optimization and Application for Hydraulic Electric Hybrid Vehicle. Energies 2020, 13, 322. [CrossRef]

2. Liao, Y.H. A Step Up/Down Power-Factor-Correction Converter with Modified Dual Loop Control. Energies 2020, 13, 199. [CrossRef]

3. Wu, C.H.; Xu, Y.X. The Optimal Control of Fuel Consumption for a Heavy-Duty Motorcycle with Three Power Sources Using Hardware-in-the-Loop Simulation. Energies 2020, 13, 22. [CrossRef]

4. Tsai, C.T.; Beza, T.M.; Wu, W.B.; Kuo, C.C. Optimal Configuration with Capacity Analysis of a Hybrid Renewable Energy and Storage System for an Island Application. Energies 2020, 13, 8. [CrossRef]

5. Li, J.Y.; Wu, T.L.; Chi, W.M.; Hu, Q.C.; Meen, T.H. Integrated Analysis of Influence of Multiple Factors on Transmission Efficiency of Loader Drive Axle. Energies 2019, 12, 4540. [CrossRef]

6. Yu, W.N.; Li, S.W.; Zhu, Y.H.; Yang, C.F. Management and Distribution Strategies for Dynamic Power in a Ship's Micro-Grid System Based on Photovoltaic Cell, Diesel Generator, and Lithium Battery. Energies 2019, 12, 4505. [CrossRef]

7. Lin, Y.T.; Cho, C.C. Analysis of Energy Flux Vector on Natural Convection Heat Transfer in Porous Wavy-Wall Square Cavity with Partially-Heated Surface. Energies 2019, 12, 4456. [CrossRef]

8. Luo, W.J.; Faridah, D.; Fasya, F.R.; Chen, Y.S.; Mulki, F.H.; Adilah, U.N. Performance Enhancement of Hybrid Solid Desiccant Cooling Systems by Integrating Solar Water Collectors in Taiwan. Energies 2019, 12, 3470. [CrossRef]

9. Hsueh, Y.M.; Ittangihala, V.R.; Wu, W.B.; Chang, H.C.; Kuo, C.C. Condition Monitor System for Rotation Machine by CNN with Recurrence Plot. Energies 2019, 12, 3221. [CrossRef]

10. Chen, C.L.; Lin, D.P.; Chen, H.C.; Deng, Y.Y.; Lee, C.F. Design of a Logistics System with Privacy and Lightweight Verification. Energies 2019, 12, 3061. [CrossRef]

11. Chang, Y.C.; Tsai, C.T.; Lu, Y.L. Current Control of the Permanent-Magnet Synchronous Generator Using Interval Type-2 T-S Fuzzy Systems. Energies 2019, 12, 2953. [CrossRef]

12. Lin, W.M.; Yang, C.Y.; Tu, C.S.; Huang, H.S.; Tsai, M.T. The Optimal Energy Dispatch of Cogeneration Systems in a Liberty Market. Energies 2019, 12, 2868. [CrossRef]

13. Hsu, C.H.; Zhang, X.Y.; Lin, H.J.; Lien, S.Y.; Cho, Y.S.; Ye, C.S. Article Numerical Simulation of Crystalline Silicon Heterojunction Solar Cells with Different p-Type a-SiOx Window Layer. Energies 2019, 12, 2541. [CrossRef]

(C) 2020 by the authors. Licensee MDPI, Basel, Switzerland. This article is an open access article distributed under the terms and conditions of the Creative Commons Attribution (CC BY) license (http://creativecommons.org/licenses/by/4.0/). 